CPD article

\title{
Solution Orientated Learning: An innovative approach that promotes motivation and resilience
}

\begin{abstract}
This article explores the use of Solution Orientated Learning (SOL) as an approach to coping with formal learning and practice development needs. The article explains each step of the SOL process and gives examples related to student and qualified nurses' experiences. Time Out activities give opportunities to apply theory to practice. The authors propose that wider application of the SOL principles can support nurses in building resilience.
\end{abstract}

Aim: To empower readers with the tools and strategies that will enable them to apply the SOL approach to meet academic and practice learning needs

\section{Intended Learning Outcomes}

After reading and participating in this CPD learning you'll be able to:

- Clarify your goals

- Build your own and others' motivation

- Use the SOL approach to design achievable steps that will take you to your desired learning outcomes

- Collaborate with other people in mutually supportive peer learning experiences

- Feel in control of your learning and empowered with strategies to enable you to meet future learning goals

\section{Introduction}

In this Continuing Professional Development (CPD) article we will explain how you can use a Solution Orientated Learning (SOL) approach to meet your learning needs. This article builds on our previous one (reference here) in which we outlined the SOL approach and the theories that underpin it, and explained how it can be used to promote resilience. The article supports readers in developing the skills relevant to the Nursing and Midwifery Council (2015) themes of prioritising people, practising effectively and promoting professionalism. New draft standards of proficiency (NMC 2017) recognise the importance of self-care for building resilience, and clinical supervision and reflection for development of leadership skills. The SOL approach is ideal for those seeking guidance for meeting these requirements and for keeping knowledge and skills in general up to date. 'Time Out' exercises are included to help you embed and record the strategies, tools and skills you learn. The Time Out activities can be recorded for evidence at revalidation.

The SOL approach applies the principles and steps of Solution Focused Brief Therapy to learning. The solution focused approach in therapy is positively orientated to strengths and goals, and involves working with clients to identify how they want their lives to change and the steps needed to work toward achieving this. Similarly in learning, a solution focused orientation builds on existing capabilities towards desired learning outcomes. Both approaches are carried out using personcentred conversations that reflect Rogerian (2004) values and practices such as being genuine, having unconditional positive regard (being non-judgemental) and showing empathy for oneself or another person. The solution-focused approach to both therapy and learning is adaptable in that it can be used independently, in pairs, with a mentor, or in groups, and once learnt, the strategies can be applied across a range of situations where people want to manage different challenges. 
While mental health nursing encompasses skills and knowledge, there is an expectation that interpersonal skills are developed throughout the learning process (both pre and post qualification) in order to develop therapeutic relationships with service users. The therapeutic relationship is "the fundamental core" of mental health nursing (Moreno-Poyato et al 2016), but this is dependent on self-awareness and the ability to use 'self' as a tool for others' benefit (Delaney, Shattell and Johnson 2017). 'Being there' with people in distress challenges the nurse's interpersonal skills and ability to manage their own emotions to an extent that requires reserves of resilience, strategies for self-care and mutually supportive relationships with colleagues. Understaffed wards and large community caseloads, together with time required for administration, add to the pressures on mental health nurses (Delaney, Shattell and Johnson 2017, McTiernan and McDonald 2016).

Assessment drives learning in higher education (Biggs and Tang 2011) but we believe that this is only part of the story for nurses, whose motivation is often associated with deeply held values (Toode et al 2014). Current under-funding combined with pressures on services can lead nurses to feel overwhelmed and unequal to the task of making things right for so many vulnerable and unwell people. Those most at risk of burnout and leaving the profession are perhaps also those most emotionally committed to it (Dotson et al 2014). Therefore, we argue that learning should not just be about gaining knowledge and skills to meet external objectives, it should also be about nurses' internal experiences. The nature of professional practice means that nurses require coping mechanisms to respond to their own emotions, manage stress, be assertive, bounce back from adversity and accept the limitations of being an individual working in a challenging environment, while also having the confidence to identify what needs to change and the optimism to take on these challenges. We believe $\mathrm{SOL}$ is relevant to nurse education and ongoing professional development because nurses not only need to learn and understand vast amounts of clinical, theoretical and ethical information, they also need to be able to look after themselves and thrive in emotionally draining and physically challenging professional environments, while also juggling to meet the demands of everyday life.

In our previous article, we outlined the Solution Orientated Learning approach in more depth, in this one we give more detail, examples and practise opportunities. We hope that whatever the stage of your career or learning, the approach will support you in meeting current needs and developing skills that will sustain you as you progress.

\section{The SOL structure}

SOL uses a series of steps, drawn from Solution Focused therapy (Shennan 2014, Milner and Myers 2017), that are designed to be supportive while building on a learner's existing strengths and capabilities. The first part of the process is to identify exactly what the learner wants to learn and why. This is explored through the 'miracle question'. The next stage is 'scaling' in which the learner works out where they are now in relation to their desired learning outcome, how they have got to this level, and what strengths (such as skills knowledge, attitudes, values and support systems) have helped them get there. The 'scaffolding diagram' supports thinking about this, and solution focused strategies help the learner build motivation and develop insight into the resources and small steps they can use to achieve their goals. The learner is also encouraged here to explore when things are going well in 'problem-free talk'. The last stage is to focus on the future and the learner is asked to consider how they could transfer the strategies they have learnt to other situations where they need to learn new skills or knowledge.

Using the 'miracle question' to identify a clear learning outcome and generate motivation 
The miracle question is the first step in exploring an individual's aspirations. It clarifies what exactly a person is aiming for, while also breaking the ice with their mentor, tutor, peer or coach. Of course an individual can coach themselves too, by asking the same question. Either way, it is useful to make notes, using a framework as in Time Out 1 below. The miracle question involves imagining a 'futureperfect' state of affairs in which the problem is solved or the ambition achieved. In relation to the scaffolding diagram, the person would be metaphorically sitting at the top, or a place where they felt happy with the situation. Although a miracle is assumed to have taken place, unrealistic outcomes such as a lottery win or bringing a person back to life are not possible. The miracle should be realistic, though ambitious. The question can be asked as,

Imagine that when you wake up tomorrow morning, the problem has been solved/you have achieved your ambition. How would you know? What signs would you see? How might other people react or behave? What else might you notice?'

This question helps to clarify what is meaningful about the outcome as well as exactly what the person is aiming for. Imagining all the positive consequences helps to build motivation too. The question can be asked about big issues such as wanting to feel confident and competent in a new role, or achieving a first class degree, to smaller ones, such as overcoming temporary anxiety about performing a procedure, or working with people in distress.

The person asking the question should be a good listener and just encourage the other person (or themselves) to express how the positive outcome would look and feel in as much detail as possible.

In the example below, Jo has identified that she would like to be able to confidently offer reassurance in a difficult and challenging situation and her reply to the miracle question was,

'On a recent placement, we had a patient admitted who was very unwell and was responding to voices which resulted in him being very abusive and aggressive towards staff. My mentor was an experienced nurse who was able to de-escalate all situations involving the patient, as I watched her I was overwhelmed by her ability to calm the situation, I thought at the time that I would like to be just like her, it was amazing to see the patient go from being frightened and anxious to calm and reassured, all through talking and the way she approached him'

In this example we can see how meaningful the outcome of 'excellent intervention at a scary time' is to Jo at this stage of her career. It is also clear that the patient's experience is very important to her. For the person listening to Jo, or for Jo herself, it is useful to notice the positive underlying values that underpin her motivation and how her personal values connect to her professional identity, as a later step of the SOL process involves giving positive feedback or 'compliments'.

In the example above, it seems that Jo might be a student nurse. Her motivation might have included an excellent outcome on a practice assessment. However, it did seem as if her motivation related to deeper values about what sort of nurse she wanted to become. The intrinsic motivation created by the reward of solving problems is a powerful driver of learning (Leung, Chen and Chen 2014) and recognising and building on it is beneficial for nurses post-qualification when formal assessments may be in the past but professional development is dependent on 'lifelong learning' and different challenges arise.

Please complete the Time Out 1 Activity, considering a development need of your own.

Time Out Activity 1. Using the 'Miracle Question' 


\begin{tabular}{|l|l|}
\hline Using the 'miracle' question & $\begin{array}{l}\text { Write below an example relevant to your own } \\
\text { practice development need - give as much } \\
\text { detail as you can - don't hold back! }\end{array}$ \\
\hline What do you want to achieve? & \\
\hline $\begin{array}{l}\text { When you wake up the next morning, after the } \\
\text { miracle has happened (and your achievement is } \\
\text { realised), how would you know? Give all the } \\
\text { details, big and small! }\end{array}$ & \\
\hline How will it look? & \\
\hline How will you feel? & \\
\hline What would other people notice? & \\
\hline What would others say and do as a result? & \\
\hline Then what might happen?? & \\
\hline
\end{tabular}

This exercise can be challenging for nurses, whose cultural values tend to emphasise putting others first. However, learning to recognise and respond to one's own needs is crucial to managing longterm well-being.

\section{Scaling - with compliments and empathy}

The next step is to articulate where the person is in relation to the outcome they want. In Solution Focused Therapy a scale of 1 to 10 is used to identify how far a client has come in coping with the issue that brought them to the therapist (Shennan 2014, Milner and Myers 2017). In SOL, the same scale can be used, but a useful alternative scale is the 'scaffolding diagram'. The scaffolding diagram was designed as an aid to promote focused conversations that acknowledge feelings, measure progress and stimulate ideas about strategies. It is related to the 'Blobs tree' (Wilson and Long 2017) often used in counselling and for pre and post training evaluation. At the same time the scaffolding diagram acknowledges the relevance of Vygotsky's (1978) concepts, in particular the 'Zone of Proximal Development' (ZPD) and 'scaffolding'. The ZPD is the area of learning that is currently a little out of reach, but which can be achieved with the help of a more knowledgeable or experienced facilitator, a mentor or peer with whom the learner can interact and build understanding through working together collaboratively.

Scaffolding is both a literal and metaphorical building support system; in learning it refers to how understanding is built through supported steps, then as learning becomes embedded the support can gradually be dismantled or fade away, with the pace of change and decisions about goals and strategies being personal choices. Following the answer to the miracle question, the person is asked to identify where on the scaffolding they would be when the miracle has 'come true' and where they are now. This is useful because not everybody is aiming to be at the top or to achieve 'ten out of ten', it may be that an in-between amount of progress is enough. So the learning outcome is defined and owned by the person involved, who at this point will have identified that there is a gap between their current situation and where they want to be. By showing where they are on the scaffolding, 
they then will probably also reveal that they have already made some progress towards the ideal, and perhaps something about their feelings about this.

Approaching a new learning challenge or confronting a professional or personal problem is not easy, it often involves a feeling of self-exposure and anxiety; there is potential for failure or disappointment. So it is important to recognise the bravery and commitment of a person responding to a challenge. Even if the person feels they have not really 'got off the ground' they can be complimented on accepting the need to do so. However, most people will have taken some steps towards their objective already, and be able to describe what they have done so far to help themselves.

At this point the person is complimented on their attitude and progress so far. This might involve recognition of some of the difficulties the person has faced and how despite their situation they have made some changes that help them towards their goal. So, for Jo, who pointed to herself on the first level of the scaffolding, her mentor might remark on how despite her anxiety she has been able to able to observe the intervention and has communicated warmly and reassuringly with her patients. Her mentor would then ask Jo how she got to the first level, showing empathy with Jo's difficulty. Perhaps Jo replied:

"Well, even though I don't feel confident about managing or being directly involved in a situation like this, I was able to identify some of the skills necessary to help"

Her mentor could acknowledge this, then ask Jo how she got to this level. This helps both to develop understanding of the specific strengths and resources that Jo could use again. Jo replies,

"I observed several of the situations where de-escalation techniques were used and read some articles about the benefits, remaining calm and keeping my own emotions in check, using non-verbal cues. When it's written down, it looks so simple but seeing it in practice means that there must be something else involved? Experience? Empathy? Self-awareness? I can role-play this in the skills lab and get feedback on my interventions"

Jo's reply is helpful as it identifies how she has several strategies that she could use again, as she takes the next step up the scaffolding within her ZPD, supported by her mentor. One of the principles taken from Solution Focused Therapy is that if something works, the client should do more of it. Jo could then be encouraged to think about how she could build her confidence further using the strategies she has identified, so that she feels ready to engage more with people in extreme distress.

The transition to professional practice at the end of pre-registration nurse training can be particularly stressful as nurses complete more difficult assessments and placement responsibilities while feeling unprepared for the challenges that lie immediately ahead (Edwards et al 2016). These anxieties reflect the realities of being a newly qualified nurse, who report concerns around workloads, professional conflicts and inadequate preparation for their role (Suresh et al 2013). A SOL approach to these stages of professional life offers a structure within which nurses can make sense of and address difficult experiences independently, with a peer, tutor, mentor or preceptor support.

\section{Time Out Activity 2}

In relation to your own development need, practice completing this middle stage of SOL. Use the box as a record. 


\begin{tabular}{|l|l|l|}
\hline $\begin{array}{l}\text { Where I am now on the } \\
\text { scaffolding diagram }\end{array}$ & $\begin{array}{l}\text { Be non-judgemental and } \\
\text { empathetic with yourself } \\
\text { throughout the process }\end{array}$ \\
\hline $\begin{array}{l}\text { How I got to this stage/what I } \\
\text { have done already to enable } \\
\text { progress }\end{array}$ & $\begin{array}{l}\text { Give details, as this will help } \\
\text { with the next stage } \\
\text { Be prepared to 'pat yourself } \\
\text { on the back' }\end{array}$ \\
\hline $\begin{array}{l}\text { Compliment yourself on your } \\
\text { achievements and } \\
\text { determination! }\end{array}$ & $\begin{array}{l}\text { Don't be embarrassed } \text { - if you } \\
\text { were doing this for a friend } \\
\text { you would feel confident to } \\
\text { give positive feedback }\end{array}$ \\
\hline $\begin{array}{l}\text { The strategies that worked } \\
\text { that I could use again for next } \\
\text { steps }\end{array}$ & \begin{tabular}{l} 
These could be bullet-pointed \\
\hline $\begin{array}{l}\text { Other resources (eg. } \\
\text { transferable skills, clinical } \\
\text { supervision meetings, people } \\
\text { in my network, training } \\
\text { opportunities eg free online } \\
\text { learning) that could help me } \\
\text { progress }\end{array}$
\end{tabular} & $\begin{array}{l}\text { Make a list - if not used now, } \\
\text { these resources might be } \\
\text { useful later. You could also } \\
\text { consider how your own skills } \\
\text { might be useful to others in } \\
\text { your network, for reciprocal } \\
\text { support }\end{array}$ \\
\hline
\end{tabular}

After completing this exercise you should be able to see a route upwards on the scaffolding diagram, and perhaps will already be considering the strategies you can use to build the expertise and resilience you need to move forwards.

Different, more complex challenges arise as a nurse's career progresses. It is hard to prepare for the problems associated with managing difficult co-workers, arguing for change in under-resourced units, promoting positive risk management, raising concerns about care, excessive demands and time management, adjusting to (or challenging) workplace cultures and so on. It is common for newly qualified nurses to feel isolated and overwhelmed by the range of their responsibilities (Draper 2013). There is a risk that nurses internalise negative feelings about their coping abilities, even though there is extensive evidence to suggest that this is an almost universal experience, more related to the context of care than the individual characteristics of those providing it (Horsburgh and Ross 2013, Teoh et al 2014, Hussein et al 2017). Empathy and a non-judgemental approach towards oneself and colleagues is part of the peer support that helps nurses in difficult times. In the scaffolding diagram, there are ladders, to represent resources, but also other people, many of whom will have experienced similar struggles and who can be part of a solution. With a sympathetic listener, the scaffolding diagram can help with articulation of subtle or complicated feelings about the 'presenting issue' while leading to a conversation about sustaining the nurse's own well-being and developing alternative responses.

\section{Exceptions and problem-free talk}

There are usually times when even the most difficult problem does not feel so bad. In Solution Focused Therapy clients are encouraged to think and talk about the times when everything is going well. It is easy, when stressed, to focus just on the negatives, but this can make a person feel worse. 'Problem-free talk' reinforces awareness of strengths while reminders of positive outcomes help restore self-esteem and motivation. 
Perhaps a shift goes well, a stressed colleague is calmer or a peer acknowledges similar feelings. When someone is worried about an issue they often overlook the 'exceptions', but these times hold clues about where solutions already lie so should be explored. If working with a colleague, you could ask, 'tell me about when things are ok?'

Time Out 3. Considering again your own goal or need, describe times when the identified issue is not a problem.

- What are you doing then?

- When does it happen?

- Who are you with?

- How does it feel?

- What clues have you found here about your next small steps towards your goal?

Taking a positive, solution-orientated approach does not mean ignoring difficulties. Sometimes it is necessary to 'let off steam' or to share sadness and this is completely understandable. The SOL approach asks the learner to put the difficulties aside for a while so as to re-energise the mind, using the person's strengths to move forwards towards solutions that fit with the individual's values. Looking over your notes from Time Out 3, you may be able to identify how you feel when things are going well and how this resonates with your own deeply-held values and motivations.

\section{Future focus}

The final stage of the SOL process is to incorporate the solution focused skills learnt into a repertoire of behaviours, so that they can be practised, adapted and re-used to address future challenges. Nurses work in teams and have an extensive peer group of potential mutual supporters who can become each other's peer support system. The skills, knowledge, expertise, resources and support system each individual grows becomes their 'platform' for future success. The SOL approach can be incorporated into professional and personal life, as effective strategies (including consulting peers and knowing when to ask for help) are transferred to address each new learning or coping need.

Time Out 4. Write a reflective account of your learning from taking part in the SOL approach. Emphasise the strategies you will be able to use again when you face different hurdles. Aim to be empowering and positive about the strengths you recognise and that which could be developed further. If you feel a framework for reflection is useful, we recommend Clarke's (2017) approach which emphasises the need to be empathic and person-centred with yourself.

SOL is a useful coaching tool and can also be used as an element of clinical supervision and for leadership development. Research into nurse burnout and quality of care indicates that nurses' sense of job-control and the support and guidance of their supervisor is central to delivery of person-centred care (Willemse et al 2015). Engagement, which is promoted by the SOL approach of building on strengths, is a moderator of burnout (Garcia-Serrera et al 2016). Therefore, a SOL approach could contribute to nurse retention.

Time Out 5 As a nurse you are a leader within your team. Consider the colleagues whose professional development is central to your team's or organisation's success (this will probably be all of you!) Make notes on how you could have a person-centred conversation with a junior colleague or student nurse about their experiences and how you might use the SOL approach to learn about their values and motivations, then support them in taking small steps to achieve their identified need or goal. 


\title{
Conclusion
}

Mental health nursing is a challenging profession in which nurses are expected to manage their own and others' often overwhelming emotional needs. Mental health nurses are expected to be competent, professional practitioners, coping in pressured environments, often with minimal ongoing opportunities for learning or professional support. Resilience is essential, but is dependent on mutual support as well as internal resources. The SOL approach offers a strategy to aid nurses in applying the optimism, commitment and core values in situations where learning, growth and motivation are central to overcoming challenges.

In this article the authors have outlined the details of how the SOL approach can be applied to meet mental health nurses' development needs. We hope that the time out activities will support them in achieving their goals and developing strategies that will be transferable to future challenges. The SOL approach can be used independently, together with a peer or by a mentor or tutor with a supervisee. Embedding a positive solution-orientated approach to learning in practice and nurse education could enhance resilience for nurses and contribute to nurse retention.

\author{
Notes to put with the scaffolding drawing \\ Where are you on this picture? \\ Where are you aiming to be, and what does that look like? \\ How did you get to the point you're at now? \\ Well done! \\ What could you do again that's already worked for you? \\ What else could you use to help you?
}

\section{References}

Biggs J, Tang C (2011). Teaching for quality learning at university. Maidenhead, McGraw-Hill.

Clarke N (2017) The Student Nurse's Guide to Successful Reflection: Ten Essential Ingredients Maidenhead. Open University Press

Delaney K, Shattell M, Johnson M. (2017) Capturing the Interpersonal Process of Psychiatric Nurses: A Model for Engagement. Archives of Psychiatric Nursing. 31, 634-640.

Dotson M, Dave D, Cazier J, Spaulding T (2014). An empirical analysis of nurse retention: what keeps RNs in nursing? Journal of Nursing Administration, 44, 2, 111- 116.

https://doi.org/10.1097/NNA.0000000000000034

Draper J (2013) Student Nurse's Experiences of Becoming a Registered Nurse. Available from:

http://www.open.edu/openlearn/bodymind/health/nursing/student-nurses-experiences-becomingregistered-nurse

Edwards D, Hawker C, Carrier J, Rees, C (2015). A systematic review of the effectiveness of strategies and interventions to improve the transition from student to newly qualified nurse. International Journal of Nursing Studies. 52, 1254-1268.

Garcia-Sierra R, Fernandez-Castro J, Martinez-Zaragoza F (2016). Relationship between job demand and burnout in nurses: does it depend on work engagement? Journal of Nursing Management. 24, 780-788. 
Horsburgh D, Ross J (2013). Care and compassion: the experiences of newly qualified staff nurses. Journal of Clinical Nursing. 22, 1124-1132.

Hussein R, Everett B, Ramjan M, Hu W, Salamonson Y (2017). New graduate nurses' experiences in a clinical specialty: a follow up study of newcomer perceptions of transitional support. BMC Nursing. 16. 42 DOI: 10.1186/s12912-017-0236-0

Leung K, Chen T, Chen, G. (2014) Learning goal orientation and creative performance: The differential mediating roles of challenge and enjoyment intrinsic motivations. Asia Pacific Journal of Management 31, 811-834.

McTiernan K, McDonald N. (2015). Occupational stressors, burnout and coping strategies between hospital and community psychiatric nurses in a Dublin region. Journal of Psychiatric and Mental Health Nursing. 22, 208-218.

Milner J, Myers S (2017) Creative ideas for Solution Focused Practice Jessica Kingsley. London.

Moreno-Poyato A, Montesó-Curto P, Delgado-Hito P, Suárez-Pérez R, Aceña-Domínguez R, CarrerasSalvador R, Leyva-Moral J, Lluch-Canut T, F. Roldán-Merino J. (2016) The Therapeutic Relationship in Inpatient Psychiatric Care: A Narrative Review of the Perspective of Nurses and Patients. Archives of Psychiatric Nursing. 30, 782-787.

Nursing and Midwifery Council (2015) The Code. Professional standards of practice and behaviour for nurses and midwives https://www.nmc.org.uk/globalassets/sitedocuments/nmc-publications/nmccode.pdf accessed 4.10 .17

Nursing and Midwifery Council (2017) Future Nurse Standards and education framework: Consultation https://www.nmc.org.uk/globalassets/sitedocuments/councilpapersanddocuments/council2017/council-item-7-may-2017.pdf accessed 4.10.17

Rogers C (2004) On Becoming a Person Constable and Robinson. London.

Shennan G (2014) Solution Focused practice: Effective communication to facilitate change Palgrave Macmillan. Basingstoke.

Suresh P, Matthews A, Coyne I (2013) Stress and stressors in the clinical environment: a comparative study of fourth-year student nurses and newly qualified general nurses in Ireland. Journal of Clinical Nursing. 22, 5-6.

Teoh Y, Pua L, Chan, M (2013) Lost in transition - A review of qualitative literature of newly qualified Registered Nurses' experiences in their transition to practice journey. Nurse Education Today. 33, 143-147.

Toode K, Helminen M, Suominen T, Helminen M, Routsalo P, Toode K (2014). Hospital nurses' individual priorities, internal psychological states and work motivation. International Nursing Review. $61,361-370$

Vygotsky L (1978) Mind in society: The development of higher psychological processes. Cambridge: Harvard University Press.

Willemse B, De Jonge J, Smit D, Visser Q, Depla M, Pot A (2015). Staff's person-centredness in dementia care in relation to job characteristics and job-related well-being: a cross-sectional survey in nursing homes. Journal of Advanced Nursing. 71, 404-416.

Wilson P, Long I (2017) ( $2^{\text {nd }}$ Edition) The Blobs Training Manual Abingdon. Routledge. 
